\title{
Children with vesico-ureteric reflux have joint hypermobility and occasional TNXB sequence variants
}

Fatima Tokhmafshan, MSc ${ }^{1}$; Jasmine El Andalousi, MSc ${ }^{2}$; Vasikar Murugapoopathy, BSc ${ }^{1}$; Marie-Lyne Fillion, $\mathrm{MSc}^{1}$; Sarah Campillo, $\mathrm{MD}^{3}$; John-Paul Capolicchio, MD ${ }^{4}$; Roman Jednak, $\mathrm{MD}^{4}$; Mohamed El Sherbiny, MD ${ }^{4}$; Sophie Turpin'; Joost Schalkwijk, $\mathrm{PhD}^{6}$; Ken-Ichi Matsumoto, $\mathrm{PhD}^{7}$; Patrick D. Brophy, $\mathrm{MD}^{8}$; Rasheed A. Gbadegesin, MD ${ }^{9}$; Indra R. Gupta, $\mathrm{MD}^{1,3,4}$

${ }^{1}$ Department of Human Genetics, McGill University, Montreal, QC, Canada; ${ }^{2}$ Research Institute of McGill University Health Centre, Montreal Children's Hospital, Montreal, QC, Canada; ${ }^{3}$ Department of Pediatrics, Montreal Children's Hospital, McGill University, Montreal, QC, Canada; ${ }^{4}$ Department of Pediatric Surgery, Division of Pediatric Urology, Montreal Children's Hospital and McGill University, Montreal, QC, Canada; ${ }^{5}$ Department of Medical Imaging, Centre Hospitalier Universitaire Sainte-Justine, Université de Montréal, Montreal, QC, Canada; ${ }^{6}$ Department of Dermatology, Nijmegen Centre for Molecular Life Sciences, Radboud University Nijmegen Medical Centre, Nijmegen, The Netherlands; ${ }^{7}$ Department of Biosignaling and Radioisotope Experiment, Interdisciplinary Center for Science Research, Organization for Research and Academic Information, Shimane University, Izumo, Shimane, Japan; ${ }^{8}$ Department of Pediatrics, Golisano Children's Hospital, University of Rochester Medical Center, Rochester, NY, United States; ${ }^{9}$ Department of Pediatrics, Division of Nephrology, Duke University Medical Center, Durham, NC, United States

Acknowledgements: The authors would like to thank the children and the families that participated in this study.

Funding: This study supported by the Canadian Institute of Health Research operating grant and Fondation des Etoiles grant to Dr. Gupta.

Cite as: Can Urol Assoc J 2019 November 5; Epub ahead of print. http://dx.doi.org/10.5489/cuaj.6068

Published online November 5, 2019

$* * *$

\section{Abstract}

Introduction: To consider alternative mechanisms that give rise to a refluxing uretero-vesical junction (UVJ), we hypothesized that children with a common heritable urinary tract defect, vesico-ureteric reflux (VUR), may have a defect in the extracellular matrix composition of the UVJ and other tissues that would be revealed by assessment of the peripheral joints. Hypermobile joints can arise from defects in the extracellular matrix within the joint capsule that affect proteins, including Tenascin XB.

Methods: We performed an observational study of children with familial and non-familial VUR to determine the prevalence of joint hypermobility, renal scarring, and DNA sequence variants in Tenascin XB. 
Results: The majority of children, 27/44, exhibited joint hypermobility using the Beighton scoring system. This included $15 / 26$ girls $(57.6 \%)$ and $12 / 18$ boys $(66.6 \%)$, which is a significantly higher prevalence for both sexes when compared to population controls $(\mathrm{p}<0.005)$. We found no association between joint hypermobility and renal scarring. Seven of 49 children harbored rare pathogenic sequence variants in $T N X B$, and two also exhibited joint hypermobility. No sequence variants in TNXB were identified in 25/27 children with VUR and joint hypermobility. Due to the observational design of the study, there was missing data for joint hypermobility scores in six children and for DMSA scans in 17 children.

Conclusions: We observed a high prevalence of VUR and joint hypermobility in children followed within a tertiary care pediatric urology clinic. While mutations in TNXB have been reported in families with VUR and joint hypermobility, we identified only two children with these phenotypes and pathogenic variants in TNXB. We, therefore, speculate that VUR and joint hypermobility may be due to mutations in other extracellular matrix genes.

\section{Introduction}

Vesico-ureteric reflux (VUR) is a congenital defect of the uretero-vesical junction (UVJ) that results in the retrograde flow of urine from the bladder towards the kidneys. The ability of the UVJ to occlude the ureteral orifice requires adequate musculature within the intravesical portion of the ureter and sufficient collagen fibers to maintain its tensile strength. ${ }^{1,2}$ VUR affects a variable number of children ranging from 1-25\% of the population and may result in recurrent pyelonephritis that can produce scars with loss of function. ${ }^{3,4,5}$ Renal scarring associated with VUR continues to be a relatively common cause of chronic kidney disease in children.

To consider alternative mechanisms that give rise to a refluxing uretero-vesical junction (UVJ), we hypothesized that children with a common heritable urinary tract defect, vesicoureteric reflux (VUR), may have a defect in the extracellular matrix composition of the UVJ and other tissues that would be revealed by assessment of the peripheral joints. Several papers have reported that children with primary VUR are at higher risk for generalized joint hypermobility or "double jointedness" which raises the intriguing possibility that there are common defects in the extracellular matrix of the joint capsules and the UVJ that result in hypermobile joints and a refluxing UVJ. ${ }^{6,7}$ Indeed, we discovered two families with dominantly inherited VUR and joint hypermobility and found that these phenotypes mapped to a locus on chromosome 6 . Using whole exome sequencing, we determined that each family harbored a heterozygous mutation in a gene that encodes an extracellular matrix glycoprotein known as Tenascin XB. ${ }^{8,9}$ Tenascin $\mathrm{XB}$ is a large glycoprotein within the extracellular matrix that interacts with the fibrillary collagens, the fibril-associated collagens, and the proteoglycan, decorin. ${ }^{10}$ The protein consists of the Nterminal oligomerization domain, the epidermal growth factor (EGF)-like repeats, the fibronectin (FN) type III repeats, and a fibrinogen (FBG)-like domain at the C-terminus. ${ }^{10}$ Autosomal recessive mutations in Tenascin $X B$ have been reported in individuals with classical-like Ehlers- 
Danlos syndrome that encompasses skin hyperextensibility, skin ecchymoses, and joint hypermobility, typically from large deletions or truncating mutations. ${ }^{11}$ We tested children with both familial and non-familial primary VUR for joint hypermobility and demonstrate that there is a high prevalence of joint hypermobility that surpasses the population prevalence. We did not find that children with VUR and joint hypermobility were more likely to have recurrent urinary tract infections, nor did they exhibit more renal scars. Children with VUR were sequenced to determine if they had mutations in Tenascin XB. While we did identify pathogenic variants in 7/49 children with VUR, only two of them exhibited joint hypermobility. This suggests that the association between VUR and joint hypermobility may be due to mutations in other genes that are relevant for the formation of the extracellular matrix in these tissues.

\section{Methods}

\section{Clinical phenotyping and joint hypermobility testing}

We previously collected DNA samples from a large cohort of 250 children with primary VUR from pediatric urology clinics. ${ }^{12}$ Within the cohort, there were familial cases and the majority of these were identified by sibling screening. The children were recruited the time of diagnosis and had a mean age of 18 months at the time of enrollment. The Beighton scoring system assesses joint hypermobility in children and is validated for use in children greater than or equal to 6 years of age. ${ }^{13}$ The scoring system uses a 9 point scale to assess the $5^{\text {th }}$ fingers, the thumbs, the elbows, the knees and the spine for joint hypermobility. Joint hypermobility is defined by a score greater than or equal to $6 / 9$ as per the guidelines established by the International Consortium of Ehlers-Danlos Syndrome. ${ }^{14}$ For this study, we re-approached children greater than or equal to 6 years of age who presented for routine followups with their treating urologist and fifty of the 250 children were eligible by age for joint hypermobility testing. Of the fifty children, forty-four consented to joint hypermobility testing, forty-nine agreed to submit DNA samples for sequencing and thirty-three underwent DMSA scans as part of routine clinical care (Table 1). The children and their parents were recruited in accordance with the research ethics board at the McGill University Health Centre (Protocol \#1389) after obtaining informed consent. All children were tested for joint hypermobility by one investigator (IRG) who was blinded to their VUR status. The grade of VUR was defined by the initial VCUG. In cases of bilateral VUR, grade was defined by the highest grade reported on either side. Nationality was determined by asking the parents their country of origin. Within the subset of fifty children, thirty-three underwent DMSA scans as requested by the treating pediatric urologist as part of routine clinical care. DMSA scans were performed at least 6 months after a urinary tract infection in the presence of recurrent febrile urinary tract infections, severe VUR (grade IV or V) and/or renal abnormalities on ultrasound. Renal scintigraphy was performed using either Tc99m-DMSA or Tc99m-Glucoheptonate and the presence of renal scarring was defined using RIVUR guidelines. ${ }^{15}$ Interpretation of the renal scan was performed by an experienced nuclear medicine 
physician (ST) who was blinded to the patient's Beighton score and Tenascin XB sequence, but not to the presence of VUR. Forty-nine patients consented to DNA sequencing and submitted saliva samples that were used for DNA extraction (Oragene DNA).

\section{Sequencing studies of children with VUR}

We used 41 primer pairs to sequence all exons, ${ }^{9,16}$ including a pair used for long-range PCR to cover the duplicated region of TNXB (exons 32-44) in 49 children with VUR. Primer sequences are provided (Supplementary Table 1). Sequenced reads were mapped to the hg19 reference genome using the PHRAP algorithm of the PHRED/PHRAP/Consed software. ${ }^{17}$ Variants were determined using Atlas-SNP2 and the PHRED-base caller to detect single nucleotide variants. Variants were annotated using 1000 genome database, ${ }^{18}$ ExAC, ${ }^{19} \mathrm{dbSNP},{ }^{20}$ RefSeq, ${ }^{21} \mathrm{HSF} 3.1,{ }^{22}$ and dbNSFP. ${ }^{23}$ Variants not reported in these databases were considered novel. Variants with a minor allele frequency (MAF) of $\leq 1 \%$ when compared to the frequency in ethnically matched populations were considered as rare variants. The predicted effects of rare variants were determined using the PROVEAN, ${ }^{24}$ SIFT, ${ }^{25}$ and Polyphen $2{ }^{26}$ algorithms. Clustal Omega alignment tool (The European Bioinformatics Institute, EMBL-EBI) was used for the phylogenetic analysis. Pathogenic coding variants were defined as such if 2 or more in silico prediction formulae reported they were deleterious.

\section{Statistical analysis}

The R-squared statistic was used to assess the relationship between the grade of VUR and the Beighton score. Chi-square analysis was used to compare the proportion of children with VUR and joint hypermobility who had renal scars on DMSA scans versus those without joint hypermobility and/or recurrent urinary tract infections.

\section{Results}

\section{Children with VUR have joint hypermobility}

We previously recruited a cohort of children with primary vesico-ureteric reflux ${ }^{12}$ and fifty were eligible for joint hypermobility testing using the Beighton scoring system. Of the fifty children, forty-four consented to joint hypermobility testing, forty-nine agreed to submit DNA samples for sequencing and thirty-three underwent DMSA scans as part of routine clinical care (Table 1). Fifteen of the 26 girls that were tested, $57.6 \%$, exhibited joint hypermobility, while 12 of the 18 boys that were tested, $66.6 \%$, exhibited joint hypermobility (Table $1 \& 2$ ) that was not significantly different ( $\left.\square^{2}=0.3613, \mathrm{P}=0.54\right)$. This observation is of interest because in most studies, girls are more hypermobile than boys, ${ }^{27,28,29}$ but in our cohort, boys were especially hypermobile. There was a significantly higher proportion of girls and boys with VUR and joint hypermobility when compared to age-matched girls $(91 / 516,26 \%)$ and boys $(67 / 530,18 \%)$ in the general population $(Z=3.45, P=0.0005$ for girls; $Z=5.04, P<0.00001$, for boys using population proportions). ${ }^{29}$ Two children had bladder diverticula in addition to VUR: one had confirmed 
joint hypermobility with a Beighton score of 9, while the other did not. The parents self-reported their nationality and the majority of the children, 36/50, were defined as European, Non-Finnish using the categories as listed in the ExAc Browser. ${ }^{19}$ Within the cohort, 31 children were diagnosed with VUR because they presented with a urinary tract infection (19 females, 12 males), and most of these children (24/31) went on to experience recurrent urinary tract infections (Table $1 \& 2$ ). The remaining 19 children that did not present with a urinary tract infection were diagnosed because of an abnormal antenatal ultrasound that prompted further postnatal evaluation including a voiding cystourethrogram. Children with VUR and joint hypermobility were not more likely to present with a urinary tract infection or to experience recurrent urinary tract infections compared to children without joint hypermobility $\left(\square^{2}=0.017, \mathrm{P}=0.89\right)$. Similarly, there was no relationship between the grade of VUR and the Beighton score $\left(\mathrm{r}^{2}=0.02, \mathrm{P}=0.3511\right)$.

Twenty-eight of the 44 children who underwent joint hypermobility testing had a DMSA scan as part of routine clinical care. While a large proportion, 16/28, had VUR, joint hypermobility and renal scars on DMSA scan, this was not statistically significant when compared to $9 / 28$ children with VUR and renal scars who did not exhibit joint hypermobility $\left(\square^{2}=0.0083, \mathrm{P}=0.92\right)$.

\section{TNXB sequence variants in children with VUR and joint hypermobility}

We previously reported an association between heterozygous sequence variants in Tenascin XB and familial VUR with joint hypermobility. ${ }^{8,9}$ We performed Sanger sequencing for this gene in 49 children with familial (8/49) and non-familial (41/49) VUR. Of the familial cases of VUR, in only one, was there a family history of joint hypermobility, and this child did not harbour a pathogenic variant in TNXB (Patient 22, Table 1). Overall, a total of 100 sequencing variants in TNXB were identified in 49 children. Of the 100 variants, 66 were exonic variants: 25 synonymous and 41 nonsynonymous. Amongst the nonsynonymous variants, 9 were defined as rare. The remaining 34 variants were intronic and 10 were splice variants. Two of the 10 splice variants were identified as rare. The eleven variants, 9 exonic and 2 intronic, were inherited as heterozygous alleles in children with non-familial VUR. The variants were analysed using prediction software as shown in Table 3. None of the patients sequenced had more than one variant. Five patients harbor pathogenic exonic variants based on deleterious scores from two or more prediction software: G878D, G1163E, P2217T, R3721W, and R4173Q (Table 3). All of the variants with the exception of the R4173Q variant affect one of the fibronectin type III (FNIII) repeat domains (Fig.1). Amongst the 5 children, 3 are female and 2 are male and 2 have high grade VUR, grade 4 or higher (Patients 12 \& 29). Four of the 5 children are not hypermobile: Patient 5, Patient 12, Patient 29 and Patient 48. Only one individual, Patient 20, is hypermobile: she has low grade VUR, grade 2, and harbors a novel variant that is predicted to be deleterious, R3721W. This variant affects exon 33 that encodes a FNIII repeat (Fig.1).

Interestingly, amongst the 5 children, she is the only one with renal scars in spite of a mild grade of VUR. Two rare intronic variants were identified that are predicted to affect a splice acceptor 
site. One male patient harbors a rare 2 base pair intronic variant that is predicted to affect a splice acceptor site (Patient 27). He has high grade VUR, joint hypermobility, and renal scars. A second patient, Patient 47, harbors a rare intronic variant, but she is not hypermobile (Table 1 and Table 3).

\section{Discussion}

While VUR remains a common pediatric disorder, the ability for clinicians to determine who will develop recurrent urinary tract infections, who will develop renal scarring, and how these patients should be managed remains unclear. An additional challenge is the fact that VUR is both genetically $30,31,32,33,34$ and phenotypically heterogeneous. The purpose of this paper was to ascertain if VUR with joint hypermobility is a common phenotype and to determine if children with VUR and joint hypermobility might be at higher risk for recurrent urinary tract infections and/or renal scars. We also sought to determine if children with VUR and joint hypermobility would be more likely to harbour coding DNA sequence variants in an extracellular matrix gene known as Tenascin XB that has been reported in familial cases of VUR and joint hypermobility. We tested 44 children with VUR for joint hypermobility and determined that the majority exhibited joint hypermobility using the Beighton scoring system. We did not observe an association between VUR, joint hypermobility and recurrent urinary tract infections nor did we observe an association between VUR, joint hypermobility and renal scars, but this may be due to the sample sizes that were assessed. We identified rare heterozygous variants in TNXB in 7/49 children with VUR of which 5 are predicted to be pathogenic exonic variants and 2 are predicted to affect a splice acceptor site. Amongst the 7 children, 2 exhibit joint hypermobility and they both have renal scars. Importantly, 25/27 children who exhibited VUR and joint hypermobility did not have DNA sequence variants in TNXB, suggesting that either other genes implicated in the composition of the extracellular matrix or environmental factors might explain the cooccurrence of these phenotypes.

Our results support the findings of van Eerde et al., ${ }^{6}$ but demonstrate that an even higher percentage of children with VUR, $66.6 \%$ of boys and $57.6 \%$ of girls exhibit joint hypermobility using cutoffs of $\geq 6$ for pre-pubertal children and $\geq 5$ for pubertal adolescents as reported by the International Consortium on the Ehlers-Danlos Syndromes. ${ }^{14}$ Our study did not include age and gender-matched controls without VUR, which ideally would have included children $\geq 6$ years of age with a normal voiding cystourethrogram. Given the radiation exposure and the need for urethral catheterization, very few children undergo a voiding cystourethrogram unless there is a high suspicion of high grade VUR. Therefore, we compared the prevalence of joint hypermobility in our VUR cohort to a population of Italian school-age children with a mean age of 10.8 years in which the prevalence of joint hypermobility was reported to be $26 \%$ in girls and $18 \%$ in boys using the same cutoff criteria as our study. ${ }^{29}$ Other population estimates of joint hypermobility using the Beighton score and/or the Bulbena score report that $18-26 \%$ of girls and $12-18 \%$ of 
boys exhibit joint hypermobility. $35,36,27,28$ Taken together, it appears that joint hypermobility is more frequently observed in children with VUR.

The majority of the children, $31 / 50$, reported at least one urinary tract infection, while 24/31 experienced recurrent urinary tract infections. While we did not formally assess for bowel and bladder dysfunction, it is possible that in addition to VUR, these children had concurrent bowel and bladder dysfunction as a risk factor for urinary tract infection. This is of interest because De Kort et al., have reported that children with generalized joint hypermobility are more likely to have lower urinary tract dysfunction including chronic constipation, urinary incontinence, and urinary tract infections. ${ }^{37}$ Therefore, we cannot exclude the possibility that children with VUR and joint hypermobility may also be at risk for bladder sphincter dysfunction possibly due to a defect in the composition of the extracellular matrix within the bladder sphincter.

Fibrillary collagens, fibrillins, elastins, glycoproteins and proteoglycans form the extracellular matrix within the joint capsule and the surrounding ligaments as well as within the UVJ and bladder. Indeed, mutations in the genes that encode these proteins result in joint hypermobility in hereditary connective tissue disorders including Cutis laxa, and Ehlers-Danlos syndrome. VUR and bladder diverticula are reported in these disorders although the penetrance of these urinary tract phenotypes has not been systematically examined. ${ }^{38}$ This suggests that a portion of children with VUR may have a global defect in the composition of the extracellular matrix that perturbs joint capsules and surrounding ligaments as well as the UVJ and the integrity of the bladder wall.

To pursue the association of VUR with joint hypermobility, we performed candidate gene sequencing for Tenascin $X B$, which is a large glycoprotein within the extracellular matrix that interacts with the fibrillary collagens, the fibril-associated collagens, and the proteoglycan, decorin. ${ }^{10}$ Autosomal recessive mutations in Tenascin $X B$ have been reported in individuals with classical-like Ehlers-Danlos syndrome that encompasses skin hyperextensibility, skin ecchymoses, and joint hypermobility, typically from large deletions or truncating mutations. ${ }^{16,11}$ While the genetic basis of autosomal dominant joint hypermobility is defined as unknown in the most recent EDS guidelines, ${ }^{14}$ we previously identified heterozygous mutations in TNXB in 5 families with VUR and joint hypermobility. ${ }^{8,9}$ Within the TNX protein, there are at least 32 fibronectin (FN) type III repeats that are postulated to be important for facilitating the extensibility of the TNX protein itself which imparts elasticity to the extracellular matrix. ${ }^{39}$ Most of the missense mutations identified to date in patients with VUR and joint hypermobility, including our study, localize to the FNIII repeats. ${ }^{8,} 9$ In this current study, we sequenced 49 children for TNXB in which the majority, 41, were sporadic cases of VUR, while the other 8 cases had a positive family history of VUR. While none of the familial cases had pathogenic variants in TNXB, 7 children with sporadic VUR did harbor pathogenic variants. One child with sporadic VUR and joint hypermobility harbored a novel variant in TNXB, R3721W, which is 
evolutionarily conserved and affects the FNIII repeat. Another child with VUR and joint hypermobility had a rare intronic variant that is predicted to affect a splice site. There were 5 other children with VUR and putative pathogenic variants in TNXB, but none of these children fulfilled criteria for joint hypermobility. Combining all of the TNXB sequencing studies, ${ }^{8,9}$ a total of 5/63 families, $8 \%$, exhibit a mutation in TNXB, and two families have both VUR and joint hypermobility. Amongst the cases of sporadic or non-familial VUR, 9/96, 9.3\%, harbor a mutation in TNXB, and of these, only three have both joint hypermobility and VUR. The TNXB protein is strongly expressed in the uroepithelium of the UVJ in children with VUR and without VUR. ${ }^{9}$ We speculate that heterozygous mutations in TNXB affect collagen deposition within the uroepithelial layer and may reduce the tensile strength of the UVJ and the joint capsule predisposing to VUR and to joint hypermobility.

There are limitations to this study. It was an observational study of children seen in a tertiary care centre in pediatric urology clinics. This factor explains the large number of severe cases of VUR within the cohort. We do not know if children with mild forms of VUR also exhibit a high prevalence of joint hypermobility. Another limitation of the study is the fact that the diagnosis of VUR is usually made at the age of 2 years, while the Beighton scoring system has been validated for use in children $\geq 6$ years. Therefore, some children submitted DNA samples at the time of diagnosis, but did not return for their follow-up appointment at the age of 6 years when joint hypermobility testing was performed. This accounts for the 6 children who did not undergo joint hypermobility testing. Another limitation is the fact that DMSA scans were requested as per clinical indications, so there was missing data on a total of 17 of the 50 children. It would have been informative to perform DMSA scans on all of the children to ascertain if there is a relationship between VUR and renal scarring, but this would require a different study design in which we would need to convince parents to permit their children to undergo a DMSA scan even when not deemed to be clinically indicated.

\section{Conclusions}

In summary, children with VUR have a higher prevalence of joint hypermobility than agematched population controls, suggesting there is a common mechanism that gives rise to both defects. From sequencing studies, it appears that mutations in TNXB do not explain most cases of VUR and joint hypermobility. This suggests that the association between VUR and joint hypermobility may be due to mutations in other genes that are relevant for the formation of the extracellular matrix in these tissues. 


\section{References}

1. Lee, B.R., et Al., A Quantitative Histologic Analysis of Collagen Subtypes: The Primary Obstructed and Refluxing Megaureter of Childhood. Urology, 1998. 51(5): P. 820-3.

2. Arena, S., et Al., Altered "active" Antireflux Mechanism in Primary Vesico-Ureteric Reflux: A Morphological and Manometric Study. BJU Int, 2007. 100(2): P. 407-12.

3. Tullus, K., Vesicoureteric Reflux in Children. Lancet, 2015. 385(9965): P. 371-9.

4. Mattoo, T.K., et Al., Renal Scarring in the Randomized Intervention for Children with Vesicoureteral Reflux (RIVUR) Trial. Clin J Am Soc Nephrol, 2016. 11(1): P. 54-61.

5. Investigators, R.T., et Al., Antimicrobial Prophylaxis for Children with Vesicoureteral Reflux. N Engl J Med, 2014. 370(25): P. 2367-76.

6. Van Eerde, A.M., et Al., Is Joint Hypermobility Associated with Vesico-Ureteral Reflux? An Assessment of 50 Patients. BJU Int, 2012. 109(8): P. 1243-8.

7. Beiraghdar, F., et Al., Vesicourethral Reflux in Pediatrics with Hypermobility Syndrome. Nephrourol Mon, 2013. 5(4): P. 924-7.

8. Elahi, S., et Al., Rare Variants in Tenascin Genes in a Cohort of Children with Primary Vesicoureteric Reflux. Pediatr Nephrol, 2016. 31(2): P. 247-53.

9. Author.

10. Valcourt, U., et Al., Tenascin-X: Beyond the Architectural Function. Cell Adh Migr, 2015. 9(1-2): P. 154-65.

11. (Schalkwijk, J., et Al., A Recessive Form of the Ehlers-Danlos Syndrome Caused by Tenascin-X Deficiency. N Engl J Med, 2001. 345(16): P. 1167-75.

12. Author

13. Smits-Engelsman, B., M. Klerks, and A. Kirby, Beighton Score: A Valid Measure for Generalized Hypermobility in Children. J Pediatr, 2011. 158(1): P. 119-23, 123 E1-4.

14. Malfait, F., et Al., The 2017 International Classification of the Ehlers-Danlos Syndromes. Am J Med Genet C Semin Med Genet, 2017. 175(1): P. 8-26.

15. Ziessman, H.A. and M. Majd, Importance of Methodology on (99m)Technetium Dimercapto- Succinic Acid Scintigraphic Image Quality: Imaging Pilot Study for RIVUR (Randomized Intervention for Children With Vesicoureteral Reflux) Multicenter Investigation. J Urol, 2009. 182(1): P. 272-9.

16. Demirdas, S., et Al., Recognizing the Tenascin-X Deficient Type of Ehlers-Danlos Syndrome: A Cross- Sectional Study in 17 Patients. Clin Genet, 2017. 91(3): P. 411-425.

17. Ewing, B. and P. Green, Base-Calling of Automated Sequencer Traces Using Phred. II. Error Probabilities. Genome Res, 1998. 8(3): P. 186-94.

18. Genomes Project, C., et A1., A Global Reference for Human Genetic Variation. Nature, 2015. 526(7571): P. 68-74.

19. Lek, M., et Al., Analysis of Protein-Coding Genetic Variation in 60,706 Humans. Nature, 2016. 536(7616): P. 285-91.

20. Sherry, S.T., et Al., DbSNP: The NCBI Database of Genetic Variation. Nucleic Acids Res, 2001. 29(1): P. 308-11.

21. O'Leary, N.A., et Al., Reference Sequence (RefSeq) Database at NCBI: Current Status, Taxonomic Expansion, and Functional Annotation. Nucleic Acids Res, 2016. 44(D1): P. D733-45. 
22. Desmet, F.O., et Al., Human Splicing Finder: An Online Bioinformatics Tool to Predict Splicing Signals. Nucleic Acids Res, 2009. 37(9): P. E67.

23. X., X. Jian, and E. Boerwinkle, DbNSFP: A Lightweight Database of Human Nonsynonymous SNPs and Their Functional Predictions. Hum Mutat, 2011. 32(8): P. 894-9.

24. Choi, Y., et Al., Predicting the Functional Effect of Amino Acid Substitutions and Indels. PLoS One, 2012. 7(10): P. E46688.

25. Kumar, P., S. Henikoff, and P.C. Ng, Predicting the Effects of Coding Non-Synonymous Variants on Protein Function Using the SIFT Algorithm. Nat Protoc, 2009. 4(7): P. 107381.

26. Adzhubei, I., D.M. Jordan, and S.R. Sunyaev, Predicting Functional Effect of Human Missense Mutations Using PolyPhen-2. Curr Protoc Hum Genet, 2013. Chapter 7: P. Unit7 20.

27. Rikken-Bultman, D.G., L. Wellink, and P.W. van Dongen, Hypermobility in Two Dutch School Populations. Eur J Obstet Gynecol Reprod Biol, 1997. 73(2): P. 189-92.

28. El-Garf, A.K., G.A. Mahmoud, and E.H. Mahgoub, Hypermobility among Egyptian Children: Prevalence and Features. J Rheumatol, 1998. 25(5): P. 1003-5.

29. Leone, V., et Al., Joint Hypermobility and Its Relationship to Musculoskeletal Pain in Schoolchildren: A Cross-Sectional Study. Arch Dis Child, 2009. 94(8): P. 627-32.

30. Darlow, J.M., et Al., Genome-Wide Linkage and Association Study Implicates the 10q26 Region as a Major Genetic Contributor to Primary Nonsyndromic Vesicoureteric Reflux. Sci Rep, 2017. 7(1): P. 14595.

31. Feather, S.A., et Al., Primary, Nonsyndromic Vesicoureteric Reflux and Its Nephropathy Is Genetically Heterogeneous, with a Locus on Chromosome 1. Am J Hum Genet, 2000. 66(4): P. 1420-5.

32. Van Eerde, A.M., et A1., Linkage Study of 14 Candidate Genes and Loci in Four Large Dutch Families with Vesico-Ureteral Reflux. Pediatr Nephrol, 2007. 22(8): P. 1129-33.

33. Weng, P.L., et Al., A Recessive Gene for Primary Vesicoureteral Reflux Maps to Chromosome 12p11- Q13. J Am Soc Nephrol, 2009. 20(7): P. 1633-40.

34. Briggs, C.E., et Al., A Genome Scan in Affected Sib-Pairs with Familial Vesicoureteral Reflux Identifies a Locus on Chromosome 5. Eur J Hum Genet, 2010. 18(2): P. 245-50.

35. Morris, S.L., et Al., Hypermobility and Musculoskeletal Pain in Adolescents. J Pediatr, 2017. 181: P. 213-221 E1.

36. Clinch, J., et Al., Epidemiology of Generalized Joint Laxity (Hypermobility) in FourteenYear-Old Children from the UK: A Population-Based Evaluation. Arthritis Rheum, 2011. 63(9): P. 2819-27.

37. De Kort, L.M., et Al., Lower Urinary Tract Dysfunction in Children with Generalized Hypermobility of Joints. J Urol, 2003. 170(5): P. 1971-4.

38. Author

39. Oberhauser, A.F., et A1., The Molecular Elasticity of the Extracellular Matrix Protein Tenascin. Nature, 1998. 393(6681): P. 181-5. 


\section{Figure and Tables}

Fig. 1. Location of pathogenic rare TNXB sequence variants within the TNXB protein domains. Five heterozygous TNXB missense variations were identified in the 49 children with vesicoureteric reflux who underwent sequencing and their corresponding amino acid changes and locations within the protein are shown. The majority of the variants affect the fibronectin type III (FNIII) modules that are implicated in binding to decorin and in mediating extensibility of the TNX protein which imparts elasticity to the tissue. One amino acid variant, R4173Q, affects the fibrinogen-like (FBG) domain which directly binds to collagen fibrils and promotes the formation of collagen fibrils. The symbol under exon 2 depicts the N-terminal oligomerization domain. The diamonds depict the EGF-like repeats. The rectangular boxes depict the FNIII repeats, and the oval depicts the fibrinogen-like domain (FBG).

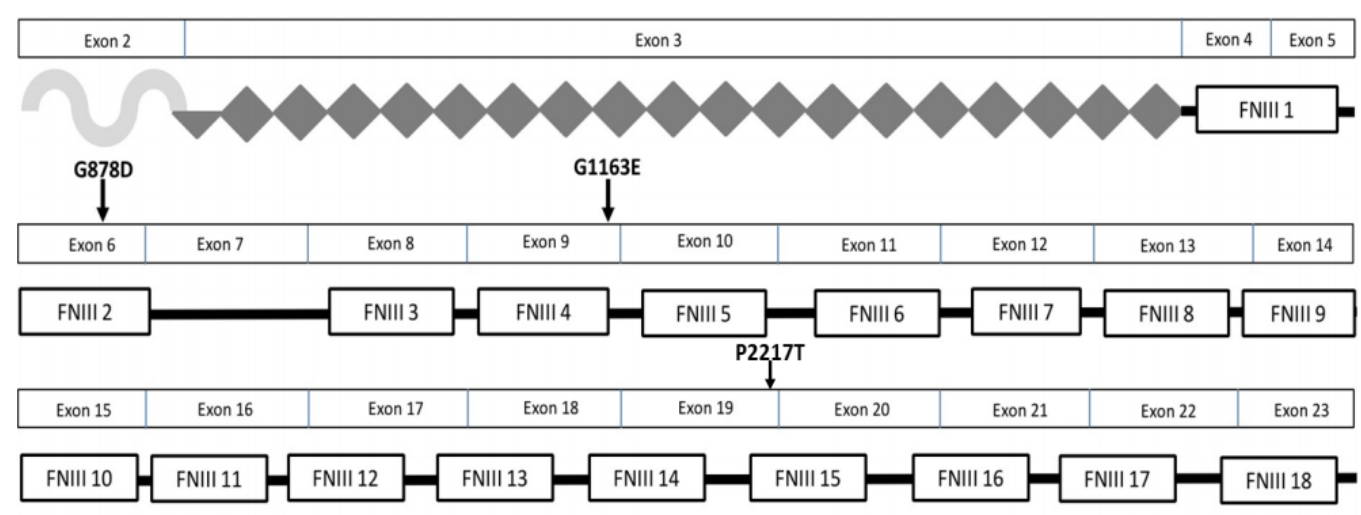

\begin{tabular}{|c|c|c|c|c|c|c|c|c|c|c|c|}
\hline Exon 24 & Exon 25 & Exon 26 & \multicolumn{2}{|c|}{ Exon 27} & \multicolumn{2}{|c|}{ Exon 28} & \multicolumn{2}{|c|}{ Exon 29} & \multicolumn{2}{|c|}{ Exon 30} & Exon 31 \\
\hline \multirow[t]{2}{*}{ FNIII 19} & FNIIII 20 & FNIIII 21 & & IIII 22 & & || 23 & & ENIII 24 & & FNIII 25 & FNIIII 26 \\
\hline & $\begin{array}{r}\text { R3721 } \\
\downarrow\end{array}$ & & & & & & & & $\begin{array}{l}\mathrm{R} 417 \\
\end{array}$ & & \\
\hline Exon 32 & Exon 33 & \begin{tabular}{l|l} 
Exon 34 & Exon 35 \\
\end{tabular} & Exon 36 & Exon 37 & Exon 38 & Exon 39 & Exon 40 & Exon 41 & Exon 42 & Exon 43 & Exon 44 \\
\hline FNIII 27 & FNIII 28 & FNIII 29 & & VIIII 30 & & IIIII 31 & $\mathrm{FN}$ & III 32 & & & \\
\hline
\end{tabular}




\begin{tabular}{|c|c|c|c|c|c|c|c|c|}
\hline $\begin{array}{l}\text { Patient } \\
\text { ID }\end{array}$ & Population & Sex & $\begin{array}{l}\text { Beighton } \\
\text { score }\end{array}$ & $\begin{array}{c}\text { UTI at } \\
\text { VUR } \\
\text { diagnosis }\end{array}$ & $\begin{array}{c}\text { Recurrent } \\
\text { UTI }\end{array}$ & $\begin{array}{c}\text { VUR } \\
\text { grade }\end{array}$ & $\begin{array}{l}\text { Family } \\
\text { history }\end{array}$ & Scarring \\
\hline 1 & Other & $\mathrm{F}$ & 4 & No & No & 3 & VUR & NA \\
\hline 2 & $\begin{array}{c}\text { European } \\
\text { (Non-Finnish) }\end{array}$ & $\mathrm{M}$ & 6 & No & No & 3 & No & NA \\
\hline 3 & South Asian & $\mathrm{M}$ & 2 & Yes & Yes & 5 & No & Yes \\
\hline 4 & Other & $\mathrm{F}$ & 8 & Yes & Yes & 3 & $\mathrm{HM}$ & Yes \\
\hline 5 & $\begin{array}{c}\text { European } \\
\text { (Non-Finnish) }\end{array}$ & $\mathrm{M}$ & 5 & Yes & Yes & 2 & No & NA \\
\hline 6 & Other & $\mathrm{M}$ & Not tested & Yes & Yes & 3 & No & Yes \\
\hline 7 & Other & $\mathrm{F}$ & 4 & Yes & Yes & 5 & No & Yes \\
\hline 8 & $\begin{array}{c}\text { European } \\
\text { (Non-Finnish) }\end{array}$ & $\mathrm{M}$ & 2 & Yes & No & 2 & No & NA \\
\hline 9 & Other & $\mathrm{M}$ & 6 & No & Yes & 3 & No & Yes \\
\hline 10 & $\begin{array}{c}\text { European } \\
\text { (Non-Finnish) }\end{array}$ & $\bar{F}$ & 6 & No & Yes & 4 & No & NA \\
\hline 11 & $\begin{array}{c}\text { European } \\
\text { (Non-Finnish) }\end{array}$ & $F$ & 7 & No & No & 2 & VUR & NA \\
\hline 12 & $\begin{array}{c}\text { European } \\
\text { (Non-Finnish) }\end{array}$ & $\mathrm{M}$ & 5 & Yes & Yes & 5 & No & Yes \\
\hline 13 & $\begin{array}{c}\text { European } \\
\text { (Non-Finnish) }\end{array}$ & $\mathrm{F}$ & 9 & Yes & Yes & 4 & HM & Yes \\
\hline 14 & $\begin{array}{c}\text { European } \\
\text { (Non-Finnish) }\end{array}$ & $\mathrm{F}$ & 6 & No & Yes & 2 & HM & Yes \\
\hline 15 & $\begin{array}{c}\text { European } \\
\text { (Non-Finnish) }\end{array}$ & $\mathrm{F}$ & 8 & Yes & Yes & 4 & HM & Yes \\
\hline 16 & $\begin{array}{c}\text { European } \\
\text { (Non-Finnish) }\end{array}$ & $\mathrm{F}$ & 6 & Yes & Yes & 3 & No & Yes \\
\hline 17 & $\begin{array}{c}\text { European } \\
\text { (Non-Finnish) }\end{array}$ & $F$ & 5 & Yes & Yes & 2 & VUR & Yes \\
\hline 18 & $\begin{array}{c}\text { European } \\
\text { (Non-Finnish) }\end{array}$ & $\mathrm{F}$ & 9 & Yes & No & 3 & VUR & NA \\
\hline 19 & $\begin{array}{c}\text { European } \\
\text { (Non-Finnish) }\end{array}$ & $F$ & Not tested & Yes & No & 3 & No & NA \\
\hline 20 & $\begin{array}{c}\text { European } \\
\text { (Non-Finnish) }\end{array}$ & $\mathrm{F}$ & 8 & No & No & 2 & No & No \\
\hline 21 & $\begin{array}{c}\text { European } \\
\text { (Non-Finnish) }\end{array}$ & $\mathrm{M}$ & 3 & Yes & No & 4 & HM & Yes \\
\hline 22 & $\begin{array}{c}\text { European } \\
\text { (Non-Finnish) }\end{array}$ & $\mathrm{F}$ & 6 & Yes & Yes & 5 & $\begin{array}{l}\text { VUR, } \\
\text { HM }\end{array}$ & NA \\
\hline 23 & $\begin{array}{c}\text { European } \\
\text { (Non-Finnish) }\end{array}$ & $\mathrm{M}$ & 9 & Yes & Yes & 2 & No & NA \\
\hline 24 & $\begin{array}{c}\text { European } \\
\text { (Non-Finnish) }\end{array}$ & $\mathrm{M}$ & Not tested & Yes & Yes & 5 & No & Yes \\
\hline
\end{tabular}




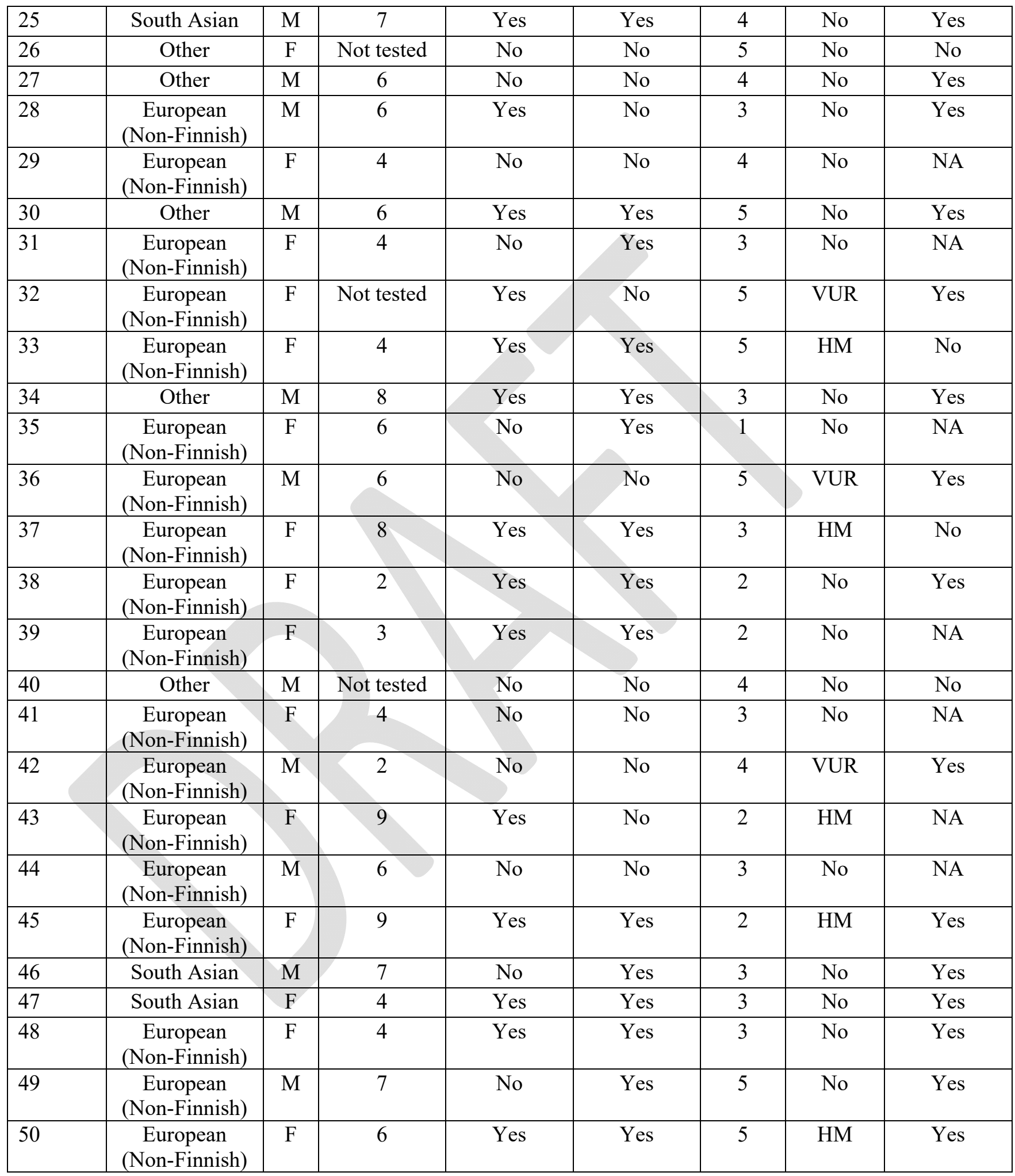

F: female; HM: hypermobility; M: male: UTI: urinary tract infection; VUR: vesico-ureteric reflux. 


\begin{tabular}{|l|c|}
\hline \multicolumn{2}{|l|}{ Table 2. Summary of clinical phenotypes of children with } \\
vesico-ureteric reflux \\
\hline Sex & 21 \\
Male & 29 \\
Female & $27(15 \mathrm{~F}, 12 \mathrm{M})$ \\
\hline HM & $17(11 \mathrm{~F}, 6 \mathrm{M})$ \\
HM & $6(3 \mathrm{~F}, 3 \mathrm{M})$ \\
No HM & \\
Not tested & $31(12 \mathrm{~F}, 19 \mathrm{M})$ \\
\hline UTI at diagnosis & $19(10 \mathrm{~F}, 9 \mathrm{M})$ \\
Yes & \\
No & 1 \\
\hline VUR grade & 11 \\
1 & 17 \\
2 & 9 \\
3 & 12 \\
4 & \\
5 & 7 \\
\hline Family history (no. of index cases) & 10 \\
VUR & 1 \\
HM & \\
VUR and HM & 28 \\
\hline Scarring & 5 \\
Renal scarring & 17 \\
No scarring & \\
No DMSA &
\end{tabular}

F: female; HM: hypermobility; M: male: UTI: urinary tract infection; VUR: vesico-ureteric reflux. 


\begin{tabular}{|c|c|c|c|c|c|c|c|}
\hline $\begin{array}{l}\text { Patient } \\
\text { ID }\end{array}$ & $\begin{array}{c}\text { Hypermobilit } \\
\text { y status }\end{array}$ & Mutation & MAF & SIFT & Provean & Polyphen2 & $\begin{array}{c}\text { Predicted } \\
\text { effect }\end{array}$ \\
\hline 3 & $\begin{array}{c}\text { Not } \\
\text { hypermobile }\end{array}$ & G3174R & 0.0031 & 0.059 & $-4.12^{*}$ & 0.033 & Neutral \\
\hline 5 & $\begin{array}{c}\text { Not } \\
\text { hypermobile }\end{array}$ & R4171Q & Novel & $0.027^{*}$ & $-2.91^{*}$ & $0.999^{*}$ & Deleterious \\
\hline 9 & Hypermobile & E2652K & 0.0011 & 0.206 & -1.98 & $0.926^{*}$ & Neutral \\
\hline 12 & $\begin{array}{c}\text { Not } \\
\text { hypermobile }\end{array}$ & G1163E & 0.0012 & $0.037^{*}$ & $-4.19^{*}$ & $0.954^{*}$ & Deleterious \\
\hline 13 & Hypermobile & S1830R & 0.0009 & 0.071 & -1.66 & 0.039 & Neutral \\
\hline 20 & Hypermobile & R3719W & Novel & $0.011^{*}$ & $-5.18^{*}$ & $1.00^{*}$ & Deleterious \\
\hline 29 & $\begin{array}{c}\text { Not } \\
\text { hypermobile }\end{array}$ & G878D & 0.0017 & 0.151 & $-3.07^{*}$ & $1.00^{*}$ & Deleterious \\
\hline 46 & Hypermobile & G3161A & 0.0079 & 0.242 & -1.09 & 0.027 & Neutral \\
\hline 48 & $\begin{array}{c}\text { Not } \\
\text { hypermobile }\end{array}$ & $\mathrm{P} 2217 \mathrm{~T}$ & 0.0023 & $0.004^{*}$ & $-2.78^{*}$ & 0.204 & Deleterious \\
\hline 27 & Hypermobile & $\begin{array}{c}\text { Intronic } \\
\text { (Chr6:3203 } \\
5762- \\
32035763 \text {, } \\
\text { CT>TG) }\end{array}$ & 0.004 & N/A & N/A & N/A & $\begin{array}{l}\text { Possible } \\
\text { effect on } \\
\text { splicing }\end{array}$ \\
\hline 47 & $\begin{array}{c}\text { Not } \\
\text { hypermobile }\end{array}$ & $\begin{array}{c}\text { Intronic } \\
\text { (Chr6:3201 } \\
5793 \\
\mathrm{G}>\mathrm{A})\end{array}$ & 0.0018 & N/A & $\mathrm{N} / \mathrm{A}$ & N/A & $\begin{array}{l}\text { Possible } \\
\text { effect on } \\
\text { splicing }\end{array}$ \\
\hline
\end{tabular}

Joint hypermobility status was determined using the Beighton scoring system. A score of $\geq 6 / 9$ was defined as joint hypermobility. Exonic or coding variants were defined as pathogenic based on deleterious scores using two or more in silico prediction software and are indicated with a superscript asterisk symbol. SIFT scores range from $0-1.0$, with 0 most damaging. Provean scores $<-2.5$ are deleterious and $>-2.5$ are considered neutral. Polyphen 2 scores range from $0-1.0$, with 1.0 most damaging. 


\begin{tabular}{|c|c|c|}
\hline \multicolumn{3}{|c|}{ Supplementary Table 1. Primers used for sequencing of Tenascin $X B$} \\
\hline Exon & Forward primer (5'-3') & Reverse primer (5'-3') \\
\hline 3 & ATGCCACAGTCGTCACCA & AGAGCAGAGCTGGGCTACAT \\
\hline 3 & GCAATCGGTTCCAGTGTACC & GGTCGTTGCGTGTGCTTT \\
\hline 3 & GCAGTCTTCCCCTGAGTAGC & GAATGCATTTGCGACACG \\
\hline 3 & AGGCACACTCCTTGCACAC & GAGAACGGCGTGTGTGTTT \\
\hline 3 & СССТСТАСАСАСАСАСАСТGG & GGAAGGCTACGTGAGTGAGG \\
\hline 3 & CATGCTCTCССТCСАCTCTT & GTGCAAGGAGTGTGCCTGT \\
\hline 4 & GCCATCTGGACTCAACCAAT & CTGAGTAAAAGGGGCTGTGG \\
\hline 5 & GGCAGATTCCCTCTCTAGTCC & GAGATAAGGGGGATTGAGCA \\
\hline 6 & CCAGAAGCATTCAGAGGAGTC & TGGACTAGAGAGGGAATCTGC \\
\hline 7 & CCAATAACCCCAGCTCCTC & GGACTGGGGATTCCTTTCTAGT \\
\hline 8 & CCCAAAGCACTGAGAAAACC & ATCCAGGATGGAGTGAGGTG \\
\hline 9 & CTGACACAGCCAGGGTATGA & CCTATGTGGGATTTGGCTTC \\
\hline 10 & GGCAAAATGAGCTGAGAAGG & TGTCAGGCTTCCCAGAAGTT \\
\hline 11 & CTGGAGCAAGGAGAGCAACT & TTTCCATGGCTGTCATCTGT \\
\hline 12 & GGAGGAGTAAAGGGGTCAGG & GGTGACAGCGAGACTCCATC \\
\hline 13 & CAGGTGGACAAAGGGAAGAC & CCCCATCTCAGTTCACAGC \\
\hline 14 & CTGGGGCCAAATAATGGTAA & GCAGTTCTGGGTTTTTCCAG \\
\hline 15 & AAAGGGGCACAAGGAAACTT & CCCAGTCTTCCAGAAACAGC \\
\hline 16 & TTCTGAAGGCTTCTCCTCCTC & TTTCGATTGCTGACTGCTTG \\
\hline 17 & ACCAAAGAGCAAGAGGGTGA & CTTTCAGATGGCTGGGAGAG \\
\hline 18 & AGGAGATGCTGGAGGCTGTA & CCAGTCATAGCCTTGGCTTC \\
\hline 19 & AGTGAAGGCACCAGCAGAA & CCTCAACACCTCCTTGCAG \\
\hline 20 & ACCAAAGAGCAAGAGGGTGA & GCACCAGCATCCAGACTGT \\
\hline 21 & GGTACCCATGAGGGAAAGGT & CCACGACGTAAGCACATCC \\
\hline 22 & ACTGTGAGCCCCATCAAGAC & AGCAAAGCAAGTTGCCCTTA \\
\hline
\end{tabular}




\begin{tabular}{|c|c|c|}
\hline 23 & ACCAAAGAGCAAGAGGGTGA & GGGCACTTTGTGTTTTGTGA \\
\hline 24 & CATGGAAACGTGCAAAAGAA & CTTGAAGACCTGAGCACATCC \\
\hline 25 & GTCAGTCCTCAGGGAAGTGG & AACAAAAGATGGCGAGGAGA \\
\hline 26 & CGAAGACTGGAGAGACAGCA & ССТТССТCACAAGACCCAAG \\
\hline 27 & CCTGTTCTTGGGCACTTTGT & CCTCTGCAGTGGAGAAGGAG \\
\hline 28 & AAGAGGTGCCAAGATCCAAA & CCAGTCATAGCCTTGGCTTC \\
\hline 29 & ATCAGTGGGTGCTGAGGACT & GCCGCTAAGAAATGCTCACT \\
\hline 30 & GAGGGACTCACTTTCGGAGT & ATAGCAGCCCAGGAAGCTC \\
\hline 31 & TTGTCTTCAGCCCAAATGC & CTCGATCACAGCAGGGAAG \\
\hline $\begin{array}{l}32 \text { (start of } \\
\text { duplicated } \\
\text { region) }\end{array}$ & GGCCAAGCCTGGAAGATAAA & GATTGGAGACAGAAGCACAC \\
\hline 33 & CCAGGGAGAGAGGATGGAT & GTCCCCAGGAATGGAAGT \\
\hline 34,35 & GACCTAGTGCCTCAGCCA & GGCTCTCTCTACTCCGTG \\
\hline $36,37,38$ & ATGGGTGGGAGTTGAGAG & TGGAAGCTGAGCAGGTAG \\
\hline $38,39,40$ & TCTCCTCTTCCTGCTTTCCC & CCCCATCAGTCTCCATGTC \\
\hline $40,41,42,43$ & CAGGACCAGCACCATCTT & TTGAGGTTGGCGTAGTGG \\
\hline 43,44 & GCTGTCTCCTACCGAGGG & GCAGAGAAGGCTTCCTCC \\
\hline $\begin{array}{l}\text { Long range } \\
\text { primers for } \\
\text { duplicated } \\
\text { region }\end{array}$ & GTCTCTGCCCTGGGAATGA & TGTAAACACAGTGCTGCGA \\
\hline
\end{tabular}

